\title{
Plenty of moustaches but not enough women: cross sectional study of medical leaders
}

\author{
(?) (1) O OPEN ACCESS
}

\author{
Mackenzie R Wehner resident physician ${ }^{1}$, Kevin T Nead resident physician ${ }^{2}$, Katerina Linos professor \\ of law ${ }^{3}$, Eleni Linos assistant professor ${ }^{4}$
}

'Department of Dermatology, Hospital of the University of Pennsylvania, Philadelphia, PA 19104, US; ${ }^{2}$ Department of Radiation Oncology, Hospital of the University of Pennsylvania, Philadelphia, PA 19104, US; ${ }^{3}$ Berkeley Law, University of California Berkeley, CA 94720, US; ${ }^{4}$ Department of Dermatology, University of California San Francisco, 2340 Sutter Street, San Francisco CA 94143, US

\begin{abstract}
Objectives To draw attention to sex related disparities in academic medical leadership by investigating the representation of female leaders compared with leaders with moustaches.

Design Cross sectional analysis.

Setting Academic medical departments in the United States.

Participants Clinical department leaders $(n=1018)$ at the top 50 US medical schools funded by the National Institutes of Health (NIH).

Main outcome measures The proportions of female leaders and moustachioed leaders across institutions and specialties $(n=20)$. Additionally, the moustache index: the proportion of women compared with the proportion of moustaches, analyzed with multinomial logistic regression models.

Results Women accounted for $13 \%$ (137/1018) of department leaders at the top $50 \mathrm{NIH}$ funded medical schools in the US. Moustachioed leaders accounted for $19 \%$ (190/1018). The proportion of female department leaders ranged from $0 \%(0 / 20)$ to $26 \%(5 / 19)$ across institutions and $0 \%(0 / 53)$ to $36 \%(19 / 53)$ across specialties. Only seven institutions and five specialties had more than $20 \%$ of female department leaders. The overall moustache index of all academic medical departments studied was 0.72 (95\% confidence interval 0.58 to 0.90 ; $\mathrm{P}=0.004)$. Only six of 20 specialties had more women than moustaches (moustache index $>1$ ).

Conclusions Moustachioed individuals significantly outnumber women as leaders of medical departments in the US. We believe that every department and institution should strive for a moustache index $\geq 1$. Known, effective, and evidence based policies to increase the number of women in leadership positions should be prioritized.
\end{abstract}

\section{Introduction}

Medicine, a historically male dominated discipline, has undergone considerable change in sex representation in recent decades. In 1960, women accounted for only $9 \%$ of medical students in the United States, but for the past 15 years, almost $50 \%$ of medical students have been women. The proportion of women in academic medicine, however, remains low and drops with increasing academic rank: $38 \%$ of full time faculty, $21 \%$ of full professors, and $16 \%$ of deans are women. ${ }^{12}$ This is a problem not only because of the strong ethical argument for equality but also for practical reasons: in business having more women leaders has been linked with better performance. For example, one study found that top firms experience positive returns on the date that female directors are announced, and another found that the Fortune 500 companies (the 500 largest US corporations by total revenue) with the highest representation of women in senior management experience significantly higher returns on equity. ${ }^{34}$

We want to increase the representation of women in academic medical leadership by drawing attention to sex disparities. We compared the proportion of women in leadership positions with the proportion of individuals with moustaches. We chose to study moustaches as the comparator because they are rare $(<15 \%$ of men from the most recent measures available), ${ }^{5}$ and we wanted to learn if women were even rarer. Our hypothesis was that fewer women lead academic medical departments in the US than individuals with moustaches. 


\section{Methods}

\section{Setting and participants}

This was a cross sectional study of the leaders of academic medical departments in the US. We used publicly available data (http://report.nih.gov/award) to identify the top 50 schools of medicine in the US funded by the National Institutes of Health (NIH) in 2014 (table $1 \Downarrow$ ). We used clinical specialties defined by NIH: anesthesia, dermatology, emergency medicine, family medicine, general surgery, internal medicine, neurology, neurosurgery, obstetrics and gynecology, ophthalmology, orthopedics, otolaryngology, pathology, pediatrics, plastic surgery, physical medicine and rehabilitation, psychiatry, radiology, radiation oncology, and urology.

We used institutional websites to identify the leader (such as chair, chief) of each specialty. Departmental structures vary between institutions, and regardless of structure (such as department, division), we identified the highest ranking leader in each specialty, which we refer to as a "department leader." For example, urology could be a department or a division of the department of surgery; in either case we included the highest ranking leader of urology. When institutions comprised multiple hospitals with more than one equally ranked leader in a specialty $(n=2)$, we included all equally ranked leaders. Figure $1 \Downarrow$ shows the search and inclusion strategy.

For each department leader we determined the URL of their institutional website and identified medical specialty, institution, name, and sex. To be included, leaders had to have a photo available on the webpage so we could check the presence and type of facial hair. Two authors (MRW, KTN) reviewed and collected data between 21 September 2015 and 3 October 2015. Both raters reviewed a subset of individuals $(n=50)$, and the assessment of inter-rater reliability showed perfect agreement $(\kappa=1)$.

\section{Definition of moustache}

Figure $2 \Downarrow$ shows the categories of facial hair. We defined a moustache as the visible presence of hair on the upper cutaneous lip and included both stand alone moustaches (for example, Copstash Standard, Pencil, Handlebar, Dali, Supermario) as well as moustaches in combination with other facial hair (for example, Van Dyke, Balbo, The Zappa). Department leaders with facial hairstyles that did not include hair on the upper lip (for example, Mutton Chops, Chin Curtain) were considered not to have a moustache. We evaluated each leader for the presence of facial hair regardless of sex.

\section{Statistical analysis and moustache index}

Our data represent a multinomial distribution with three mutually exclusive groups of leaders: women, men with moustaches, and men without moustaches. We used multinomial logistic regression analysis to compare the proportion of women with the proportion of moustachioed department leaders across institutions and specialties: the moustache index. Tests were considered significant if the two sided $\mathrm{P}$ value was $<0.05$. Analyses were performed with Stata version 12.0 (StataCorp, College Station, TX).

\section{Results}

There were 1018 department leaders who met inclusion criteria. Two $(0.2 \%)$ did not have a photo available and were excluded. We found that women accounted for 13\% (137/1018) of department leaders at the top $50 \mathrm{NIH}$ funded medical schools in the US. Moustachioed individuals were all men and accounted for 19\% (190/1018) of department leaders.

Figure $3 \Downarrow$ shows the proportion of female department leaders by institution, which ranged from $0 \%(0 / 20)$ to $26 \%(5 / 19)$. Only seven institutions had more than $20 \%$ female department leaders. It also shows the proportion of female department leaders by medical specialty, which ranged from $0 \%(0 / 53)$ to $36 \%$ (19/53). Only five specialties had more than $20 \%$ female department leaders: obstetrics and gynecology $(36 \% ; 19 / 53)$, pediatrics $(31 \% ; 16 / 52)$, dermatology $(23 \% ; 12 / 53)$, family medicine $(21 \% ; 9 / 43)$, and emergency medicine $(21 \% ; 11 / 53)$.

Figure $4 \Downarrow$ shows the proportion of moustachioed department leaders by institution, which ranged from $0 \%(0 / 20)$ to $37 \%$ (7/19). Nineteen institutions had more than $20 \%$ moustachioed department leaders. It also shows the proportion of moustachioed department leaders by medical specialty, which ranged from $2 \%(1 / 53)$ to $31 \%$ (17/54). Ten specialties had more than $20 \%$ moustachioed department leaders, with the thickest moustache density in psychiatry $(31 \% ; 17 / 54)$, pathology $(30 \% ; 16 / 53)$, and anesthesiology $(26 \% ; 14 / 53)$. Two specialties had fewer than $10 \%$ moustaches (general surgery $(2 \% ; 1 / 53)$ and plastic surgery $(4 \% ; 2 / 52))$.

The overall moustache index, derived from multinomial logistic regression analyses, of all academic medical departments studied was 0.72 ( $95 \%$ confidence interval 0.58 to $0.90 ; \mathrm{P}=0.004$ ).

Figure $5 \Downarrow$ shows the moustache index across institutions and specialties. Six out of 20 specialties had moustache indices $>1$, indicating that there were more women than moustaches: pediatrics (1.33), dermatology (1.50), physical medicine and rehabilitation (1.50), obstetrics and gynecology (1.90), plastic surgery (2.0), and general surgery (3.0). Table $1 \Downarrow$ and appendix 1 show individual institution and specialty level data used in the calculation of the moustache index.

\section{Discussion}

Individuals with moustaches outnumber women as department leaders in the US. Pediatrics, family medicine, obstetrics and gynecology, and dermatology have the highest proportions of women leaders and the highest moustache indices. General surgery and plastic surgery also have high moustache indices, but this was driven by the absence of moustaches rather than the number of women.

Our study builds on a recent analysis of over 90000 academic physicians, which showed that women were less likely to be full professors even after adjustment for age and research productivity. ${ }^{6}$ We believe that every department and institution should strive for a moustache index $\geq 1$. There are two ways to achieve this goal: by increasing the number of women or by asking leaders to shave their moustaches. In addition to being discriminatory, the latter choice could have detrimental effects on workplace satisfaction and emotional wellbeing of moustachioed individuals. Deans are left with one option: to hire, retain, and promote more women.

Sex discrepancies in leadership are distressingly common across specialties. Many employers have taken steps to reduce these gaps by adopting policies against discrimination and sexual harassment, by introducing family friendly benefits, and by offering paid parental leave, which have been shown to considerably improve outcomes in the female labor force. ${ }^{7}$ In medical academia, department leaders are familiar with the potentially effective strategies of mentoring, paid leave for childbearing (especially maternity leave), and tenure clock extensions, which allow new parents more time to meet requirements for promotion. ${ }^{9-12}$ 
Recent evidence from psychology, sociology, and economics, however, suggests that two additional strategies might be necessary to close the gap. Firstly, define hiring criteria in advance of evaluating candidates. ${ }^{6}{ }^{13}$ Without clearly defined criteria, evaluators unconsciously redefine what they are seeking to match the attributes of male candidates..$^{14}$ As a result, women, and especially mothers, tend to be evaluated more negatively than men with the same professional characteristics. ${ }^{15} 16$

Secondly, increase temporal flexibility in job structures. ${ }^{17}$ In many occupations, the ideal worker is one who works long hours each week over many decades. Women experience considerable penalties in status and pay for taking even a short time off to care for children. ${ }^{17}$ This penalty differs by specialty: it is lowest in specialties like pharmacy, in which organizational innovations allow workers to easily substitute for one another. ${ }^{18}$ In medicine, innovations such as creating larger practices to enable teamwork, computerized medical records, and shift work could also reduce sex inequality by reducing the premium for long hours and uninterrupted employment. ${ }^{19}$ Further strategies that increase control over work schedules could promote retention and advancement of women: having control over total hours and when you work is a predictor of career satisfaction, work-life balance, and low burnout. ${ }^{20}$ Accordingly, women physicians in "controllable lifestyle" specialties, such as dermatology and anesthesiology, tend to enjoy high levels of satisfaction. ${ }^{21}$

\section{Limitations}

To highlight the paucity of women in academic medical leadership, we wanted to choose a rare but easily identifiable comparator unrelated to promotion and achievement: the moustache. Facial hair, however, has been shown to enhance perceptions of maturity, responsibility, dominance, strength, and self confidence. ${ }^{22}{ }^{23}$ In addition, men who put on fake beards rate themselves as more masculine. ${ }^{24}$ If moustaches are linked to success, this could bias our moustache indices. Additionally, the prevalence of moustaches among physicians is unknown. We were not able to control for age, and, given that leaders are older and moustache popularity has decreased over time, ${ }^{5}$ our results might be confounded by age. Similarly, we were unable to account for the impact of ethnicity in our analysis.

Misclassification of moustaches is another potential limitation, and our data are only as accurate as the institutional websites: photos might be out of date, especially for senior staff who might strive to look younger. Also, we could not confirm that moustaches in photos were real, although two authors are trained in dermatology and skilled at examining hair growth. Finally, our sample was limited to clinical departments in NIH funded US medical schools, which could limit its generalizability.

\section{Conclusion}

We conclude that there are more moustachioed individuals than women leading US academic medical departments. Two evidence based solutions that could be applied to improve this are the predefining of hiring criteria and innovations that allow women flexibility in scheduling their working days and years. We hope that these solutions will help increase moustache indices across all specialties by raising the number of women leaders while maintaining sufficient facial hair in our workplaces.

MRW and KTN contributed equally and are co-first authors. We thank Jon Dyer for use of figure 2, John Boscardin for statistical advice, and Natalie Linos and Elizabeth Linos for content advice and editing. EL thanks the American Academy of Dermatology 2015 Leadership Forum, and KL thanks the Hellman Family Fund.
Contributions: MRW, KTN, and EL conceived and designed the project and collected data. MRW and KTN analyzed the data. MRW, KTN, KL, and EL wrote the manuscript. EL is guarantor.

Funding: This research received no specific grant from any funding agency in the public, commercial, or not-for-profit sectors.

Competing interests: MRW, KL, and EL are women. KTN is a man and does not currently have a moustache. All authors have completed the ICMJE uniform disclosure form at www.icmje.org/coi_disclosure.pdf and declare: no support from any organization for the submitted work; no financial relationships with any organizations that might have an interest in the submitted work in the previous three years; no other relationships or activities that could appear to have influenced the submitted work.

Ethical approval: This study used publicly available data and institutional review board was not required.

Transparency: The manuscript's guarantor affirms that the manuscript is an honest, accurate, and transparent account of the study being reported; that no important aspects of the study have been omitted; and that any discrepancies from the study as planned have been explained Data sharing: Statistical code and dataset are available from the corresponding author.

AAMC. The state of women in academic medicine: the pipeline and pathways to leadership. 2013. https://www.aamc.org/members/gwims/statistics/.

2 Page L. Women still face barriers to leadership roles in academic medicine. 2012. https: //www.aamc.org/newsroom/reporter/dec2012/323602/women.html.

3 Dezsö CL, Ross DG. Does female representation in top management improve firm performance? A panel data investigation. Strateg Manage J 2012;33: 1072-89doi:10. 1002/smj. 1955.

4 Terjesen S, Sealy R, Singh V. Women directors on corporate boards: a review and research agenda. Corp Gov 2009;17: 320-37doi:10.1111/j.1467-8683.2009.00742.x.

5 Robinson DE. Fashions in shaving and trimming of the beard: the men of the lllustrated London News, 1842-1972. Am J Sociol 1976:81: 1133-41doi:10.1086/226188.

6 Jena AB, Khullar D, Ho O, Olenski AR, Blumenthal DM. Sex differences in academic rank in US medical schools in 2014. JAMA 2015;314: 1149-58. doi:10.1001/jama.2015. 1068026372584

7 Linos K. Diffusion through democracy. Am J Pol Sci 2011;55: 678-95doi:10.1111/j.15405907.2011.00513.x

8 Ruhm CJ. The economic consequences of parental leave mandates: lessons from Europe. Q J Econom 1998;108-1: 285-317.

9 Yedidia MJ, Bickel J. Why aren't there more women leaders in academic medicine? the views of clinical department chairs. Acad Med 2001;76: 453-65. doi:10.1097/00001888200105000-00017 11346523

10 Travis EL, Doty L, Helitzer DL. Sponsorship: a path to the academic medicine C-suite for women faculty?Acad Med 2013;88: 1414-7. doi:10.1097/ACM. 0b013e3182a35456 23969365

11 DeCastro R, Griffith KA, Ubel PA, Stewart A, Jagsi R. Mentoring and the career satisfaction of male and female academic medical faculty. Acad Med 2014;89: 301-11. doi:10.1097/ ACM.0000000000000109 24362376

12 Dixit A, Feldman-Winter L, Szucs KA. Parental leave policies and pediatric trainees in the United States. J Hum Lact 2015;31: 434-9. doi:10.1177/0890334415585309 25948576

13 Uhlmann E, Cohen GL. Constructed criteria: redefining merit to justify discrimination. Psychol Sci 2005;16: 474-80. 15943674

14 Phelan JE, Moss-Racusin CA, Rudman LA. Competent yet out in the cold: Shifting criteria for hiring reflect backlash toward agentic women. Psychol Women Q 2008;32: 406-13doi: 10.1111/j.1471-6402.2008.00454.x.

15 Correll SJ, Benard S, Paik I. Getting a job: is there a motherhood penalty? Am J Sociol 2007;112: 1297-339doi:10.1086/511799.

16 Burgess DJ, Joseph A, van Ryn M, Carnes M. Does stereotype threat affect women in academic medicine?Acad Med 2012;87: 506-12. doi:10.1097/ACM. 0b013e318248f718 22361794

17 Goldin C. A grand gender convergence: its last chapter. Am Econ Rev 2014;104: 1091-119doi:10.1257/aer.104.4.1091.

18 Goldin C, Katz LF. The most egalitarian of all professions: pharmacy and the evolution of a family-friendly occupation. National Bureau of Economic Research, 2012doi:10.3386/ w18410.

19 Briscoe F. Temporal flexibility and careers: The role of large-scale organizations for physicians. Ind Labor Relat Rev 2006;60: 88-104doi:10.1177/001979390606000105.

20 Keeton K, Fenner DE, Johnson TR, Hayward RA. Predictors of physician career satisfaction, work-life balance, and burnout. Obstet Gynecol 2007;109: 949-55. doi:10. 1097/01.AOG.0000258299.45979.37 17400859

21 Frank E, McMurray JE, Linzer M, Elon LSociety of General Internal Medicine Career Satisfaction Study Group. Career satisfaction of US women physicians: results from the Women Physicians' Health Study. Arch Intern Med 1999;159: 1417-26. doi:10.1001/ archinte.159.13.1417 10399893

22 De Souza AAL, Baião VB, Otta E. Perception of men's personal qualities and prospect of employment as a function of facial hair. Psychol Rep 2003;92: 201-8. doi:10.2466/pro. 2003.92.1.201 12674283

23 Hellström Å, Tekle J. Person perception through facial photographs: Effects of glasses, hair, and beard on judgments of occupation and personal qualities. Eur J Soc Psychol 1994:24: 693-705doi:10.1002/ejsp.2420240606.

24 Wood DR. Self-perceived masculinity between bearded and non-bearded males. Percept Mot Skills 1986;62: 769-70doi:10.2466/pms.1986.62.3.769. 


\section{What is already known on this topic}

The number of women in medicine has increased significantly since the 1960 s, with women now accounting for nearly $50 \%$ of US medical students

The proportion of women in academic medicine is still low: only $21 \%$ of full professors are women

\section{What this study adds}

There are fewer women leading academic medical departments than individuals with moustaches Evidence based policies that increase women in leadership positions are needed

Published by the BMJ Publishing Group Limited. For permission to use (where not already granted under a licence) please go to http://group.bmj.com/group/rights-licensing/ permissions

This is an Open Access article distributed in accordance with the Creative Commons Attribution Non Commercial (CC BY-NC 3.0) license, which permits others to distribute, remix, adapt, build upon this work non-commercially, and license their derivative works on different terms, provided the original work is properly cited and the use is non-commercial. See: http://creativecommons.org/licenses/by-nc/3.0/. 


\section{Table}

\section{Table 1| Moustache indices by institution}

\begin{tabular}{|c|c|c|c|c|c|}
\hline Institution & Moustache index $(95 \% \mathrm{Cl})$ & $P$ value & No of moustaches & No of women & No of leaders \\
\hline University of Utah* & 0.00 & - & 4 & 0 & 20 \\
\hline Weill Medical College of Cornell University* & 0.00 & - & 2 & 0 & 19 \\
\hline Johns Hopkins University & 0.17 (0.02 to 1.38$)$ & 0.10 & 6 & 1 & 19 \\
\hline New York University & $0.20(0.02$ to 1.71$)$ & 0.14 & 5 & 1 & 19 \\
\hline University of Maryland Baltimore & 0.20 (0.02 to 1.71$)$ & 0.14 & 5 & 1 & 20 \\
\hline University of North Carolina Chapel Hill & 0.25 (0.03 to 2.24$)$ & 0.22 & 4 & 1 & 20 \\
\hline University of Pittsburgh & 0.25 (0.03 to 2.24$)$ & 0.22 & 4 & 1 & 20 \\
\hline Medical College of Wisconsin & 0.29 (0.06 to 1.38$)$ & 0.12 & 7 & 2 & 20 \\
\hline University of Chicago & 0.33 (0.03 to 3.20$)$ & 0.34 & 6 & 2 & 19 \\
\hline Baylor College of Medicine & $0.33(0.03$ to 3.20$)$ & 0.34 & 3 & 1 & 20 \\
\hline University of California, San Diego & $0.33(0.07$ to 1.65$)$ & 0.18 & 3 & 1 & 20 \\
\hline University of Washington & $0.40(0.08$ to 2.06$)$ & 0.27 & 5 & 2 & 20 \\
\hline Indiana University-Purdue University at Indianapolis & $0.43(0.11$ to 1.66$)$ & 0.22 & 7 & 3 & 19 \\
\hline Icahn School of Medicine at Mount Sinai & $0.50(0.13$ to 2.00$)$ & 0.33 & 4 & 2 & 20 \\
\hline Vanderbilt University & 0.50 (0.09 to 2.73 ) & 0.42 & 4 & 2 & 19 \\
\hline University of Illinois at Chicago & $0.50(0.13$ to 2.00$)$ & 0.33 & 4 & 2 & 18 \\
\hline University of Massachusetts Medical School Worcester & 0.50 (0.09 to 2.73 ) & 0.42 & 6 & 3 & 19 \\
\hline University of Alabama at Birmingham & 0.50 (0.09 to 2.73$)$ & 0.42 & 6 & 3 & 20 \\
\hline Harvard University & 0.55 (0.20 to 1.47$)$ & 0.23 & 11 & 6 & 52 \\
\hline University of California, Davis & $0.57(0.17$ to 1.95$)$ & 0.37 & 7 & 4 & 20 \\
\hline Oregon Health and Science University & 0.60 (0.14 to 2.51$)$ & 0.48 & 5 & 3 & 19 \\
\hline Northwestern University at Chicago & 0.60 (0.14 to 2.51$)$ & 0.48 & 5 & 3 & 20 \\
\hline University of Florida & $0.67(0.11$ to 3.99$)$ & 0.66 & 3 & 2 & 19 \\
\hline Case Western Reserve & 0.67 (0.11 to 3.99$)$ & 0.66 & 6 & 4 & 34 \\
\hline Yale University & $0.67(0.11$ to 3.99$)$ & 0.66 & 3 & 2 & 18 \\
\hline Medical University of South Carolina & 0.67 (0.11 to 3.99$)$ & 0.66 & 3 & 2 & 19 \\
\hline Columbia University & 0.67 (0.19 to 2.36$)$ & 0.53 & 3 & 2 & 19 \\
\hline University of Colorado Denver & 0.75 (0.17 to 3.35$)$ & 0.71 & 4 & 3 & 20 \\
\hline Duke University & 0.75 (0.17 to 3.35$)$ & 0.71 & 4 & 3 & 19 \\
\hline University of Southern California & 0.75 (0.17 to 3.35$)$ & 0.71 & 4 & 3 & 19 \\
\hline University of Michigan & 0.75 (0.17 to 3.35$)$ & 0.71 & 4 & 3 & 20 \\
\hline Stanford University & 1.00 (0.20 to 4.95$)$ & 1.00 & 4 & 4 & 18 \\
\hline University of Miami & $1.00(0.25$ to 4.00$)$ & 1.00 & 2 & 2 & 20 \\
\hline University of Virginia & $1.00(0.25$ to 4.00$)$ & 1.00 & 3 & 3 & 20 \\
\hline Boston University & $1.00(0.14$ to 7.10$)$ & 1.00 & 4 & 4 & 20 \\
\hline $\begin{array}{l}\text { Cleveland Clinic Lerner College of Medicine-Case Western Reserve } \\
\text { University }\end{array}$ & $1.00(0.20$ to 4.95$)$ & 1.00 & 3 & 3 & 20 \\
\hline Albert Einstein College of Medicine & $1.00(0.25$ to 4.00$)$ & 1.00 & 4 & 4 & 20 \\
\hline University of Rochester & $1.25(0.34$ to 4.65$)$ & 0.74 & 4 & 5 & 20 \\
\hline University of Minnesota & $1.33(0.30$ to 5.96$)$ & 0.71 & 3 & 4 & 19 \\
\hline University of Pennsylvania & $1.33(0.30$ to 5.96$)$ & 0.71 & 3 & 4 & 20 \\
\hline University of Texas Southwestern & $1.50(0.25$ to 8.98$)$ & 0.66 & 2 & 3 & 20 \\
\hline University of California, Los Angeles & $1.50(0.25$ to 8.98$)$ & 0.66 & 2 & 3 & 19 \\
\hline University of lowa & $1.50(0.25$ to 8.98$)$ & 0.66 & 2 & 3 & 19 \\
\hline Wake Forest University & 2.00 (0.37 to 10.92$)$ & 0.42 & 2 & 4 & 19 \\
\hline University of Wisconsin-Madison & $2.50(0.49$ to 12.89$)$ & 0.27 & 2 & 5 & 19 \\
\hline
\end{tabular}




\section{Table 1 (continued)}

Institution

Emory University

Dartmouth College

University of California, San Francisco

Washington University $†$

Ohio State University†
Moustache index $(95 \% \mathrm{Cl}) \mathrm{P}$ value No of moustaches No of women No of leaders

4.00 ( 0.45 to 35.79$)$

$\begin{array}{llll}0.22 & 1 & 4 & 20 \\ 0.22 & 1 & 4 & 19 \\ 0.22 & 1 & 4 & 19 \\ - & 0 & 3 & 18 \\ - & 0 & 3 & 20\end{array}$

* P value could not be calculated around moustache index of 0 .

$\dagger$ Moustache index could not be calculated (no moustaches). 


\section{Figures}

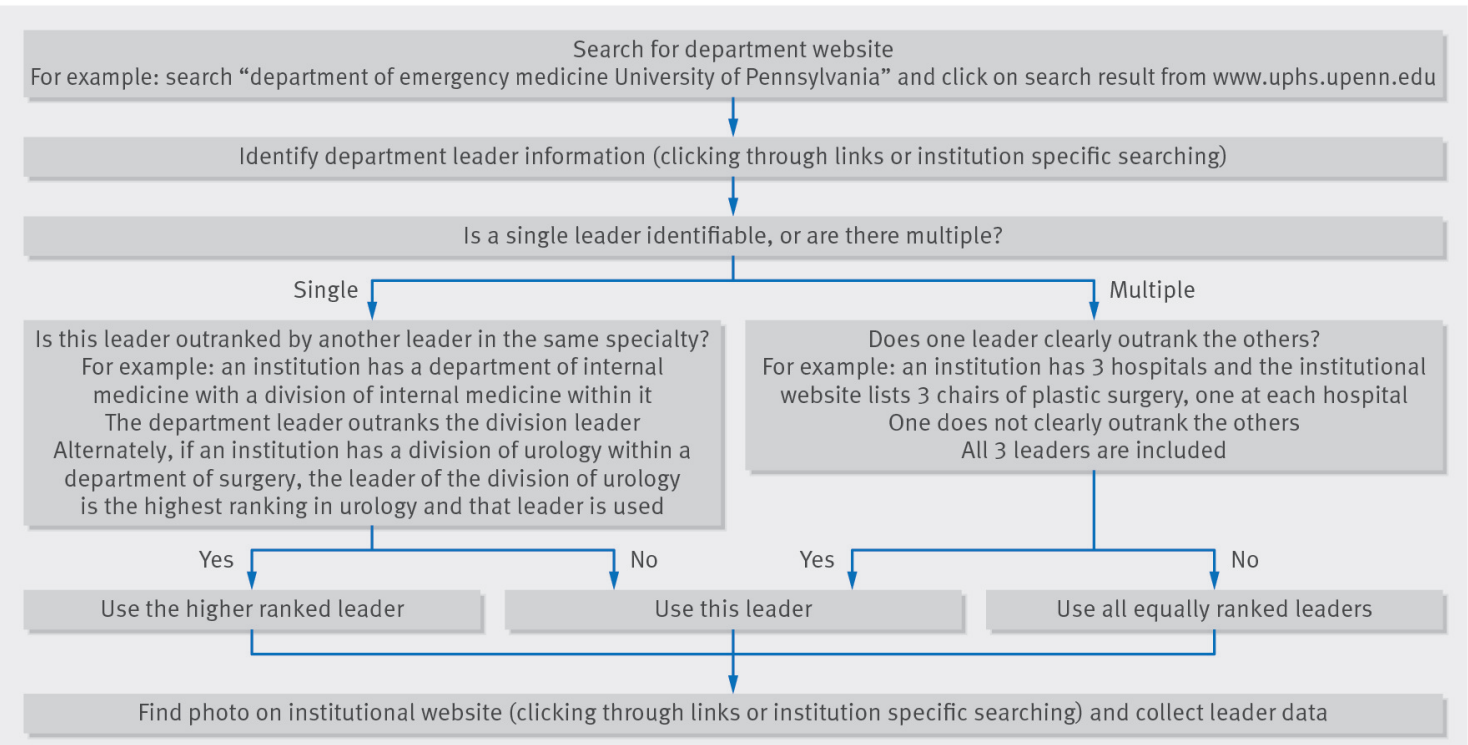

Fig 1 Flow chart of data collection

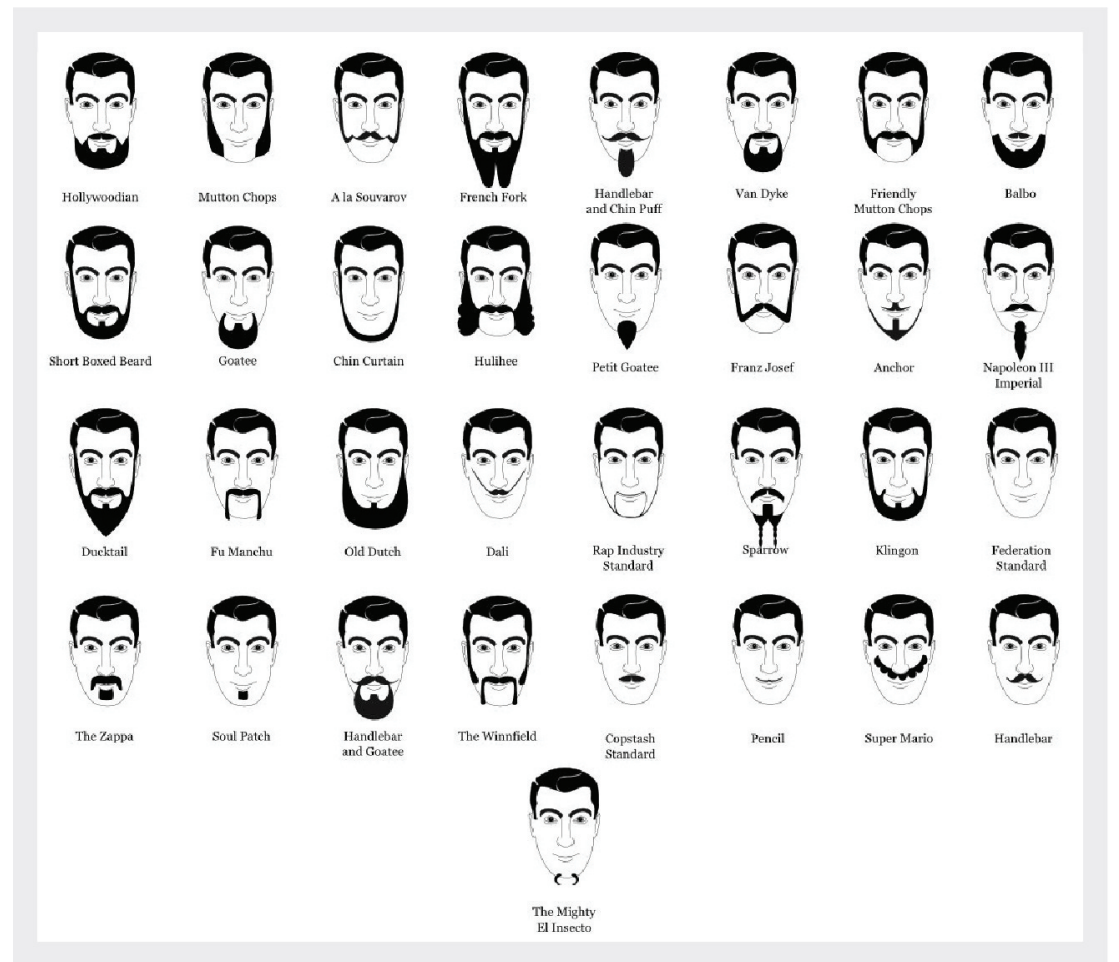

Fig 2 Facial hair categories

[Image: Image courtesy of Jon Dyer/dyers.org, with permission] 

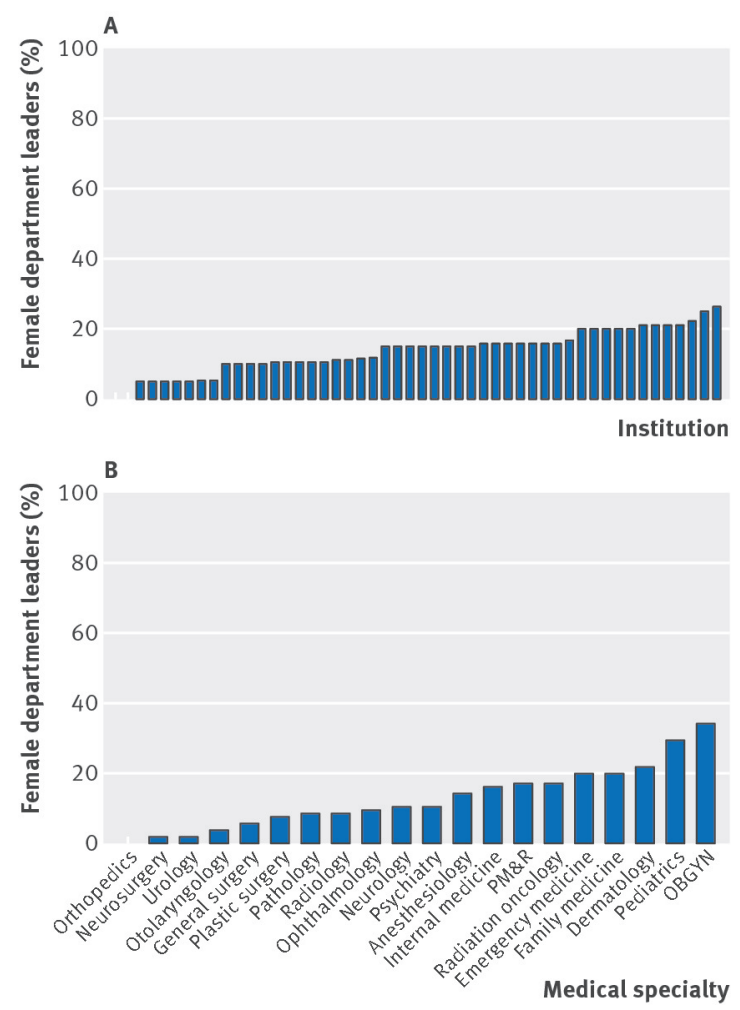

Fig 3 Percentage of female department leaders by institution and specialty. OBGYN=obstetrics and gynecology; PM\&R=physical medicine and rehabilitation
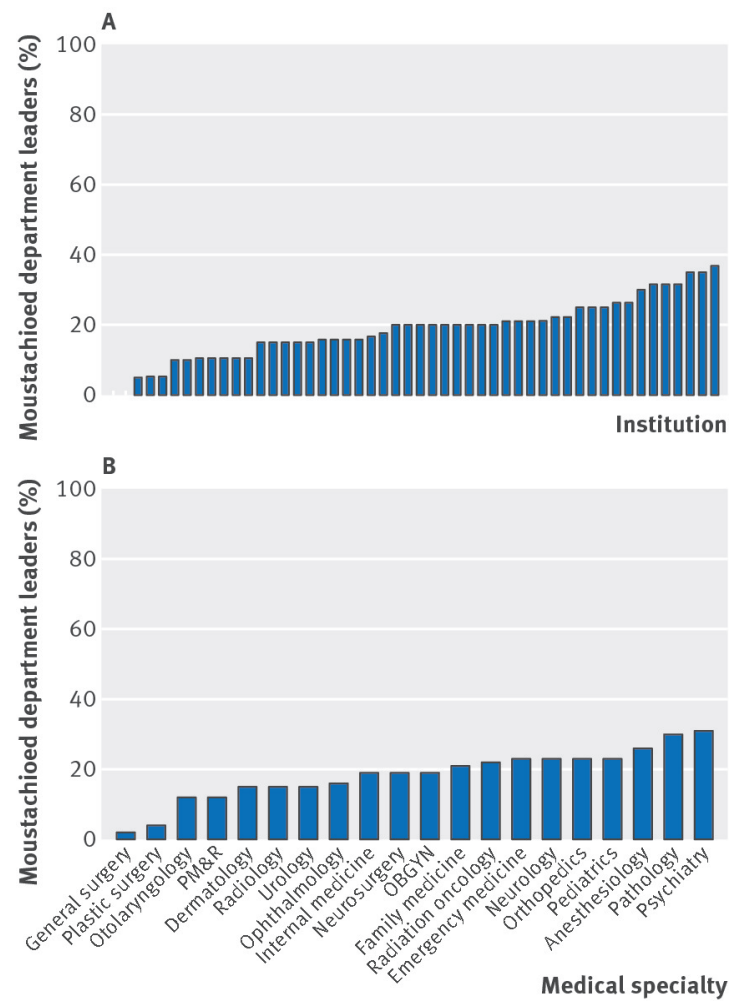

Fig 4 Percentage of moustachioed department leaders by institution and specialty. OBGYN=obstetrics and gynecology; PM\&R=physical medicine and rehabilitation 

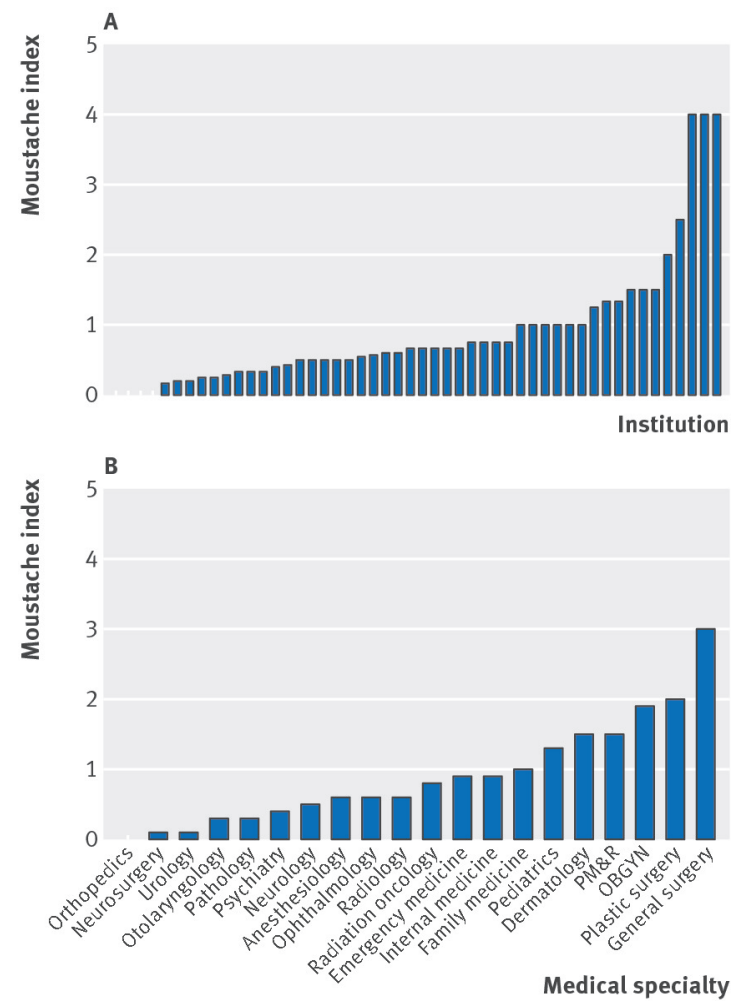

Fig 5 Moustache index (percentage of women/percentage moustachioed individuals) by institution and specialty. OBGYN=obstetrics and gynecology; PM\&R=physical medicine and rehabilitation 